\title{
CORRESPONDENCE
}

\section{THE TRANS-ANTARCTIC ASSOCIATION}

The Trans-Antarctic Association is now in a position to make grants of money to suitable expeditions or individuals for work in the Antarctic. The total sum available varies, but is of the order of $£ 1700$ a year.

Until now, the number of applications has been small and the Committee of Management feels that it may not be having the opportunity to consider some worthwhile projects.

I have therefore been instructed to write reminding you of the existence of the fund and suggesting that from time to time you may like to indicate this source of assistance to appropriate people.

Applications should be sent in before 15 February and a decision will normally be given by the end of April each year.

Briefly the objects for which the Association is established are:

(A) To promote, organize, encourage or support expeditions for the exploration of the Antarctic regions.

(B) To encourage or support education or research in the various sciences so far as they apply to the Antarctic.

(C) To encourage or support the dissemination of information acquired as a result of the foregoing objects.

ELEANOR HONNYwill

(Secretary)

The Trans-Antarctic Association

30 Gillingham Street

London, $S W 1$

11 May 1965 